\title{
Smoking rate trends of male 7th and 11th graders in Japan based on repeated, nationwide, cross-sectional surveys every 4 years from 1996 to 2008
}

\author{
Hideyuki Kanda ${ }^{1^{*}}$, Yoneatsu Osaki ${ }^{2}$, Yoshitaka Kaneita ${ }^{3}$, Osamu Itani ${ }^{4}$, Maki Ikeda ${ }^{4}$, \\ Takashi Ohida ${ }^{4}$ \\ ${ }^{1}$ Department of Epidemiology and Public Health, School of Medicine, Yokohama City University, Yokohama, Japan; \\ *Corresponding Author: hkanda@yokohama-cu.ac.jp \\ ${ }^{2}$ Department of Environmental and Preventive Health, School of Medicine, Tottori University, Yonago, Japan \\ ${ }^{3}$ Department of Epidemiology and Public Health, School of Medicine, Ohita University, Ohita, Japan \\ ${ }^{4}$ Department of Public Health, School of Medicine, Nihon University, Tokyo, Japan
}

Received 21 May 2013; revised 22 June 2013; accepted 15 July 2013

Copyright (C 2013 Hideyuki Kanda et al. This is an open access article distributed under the Creative Commons Attribution License, which permits unrestricted use, distribution, and reproduction in any medium, provided the original work is properly cited.

\begin{abstract}
Backgrounds: Smoking in childhood has become an important public health concern. Previous studies have reported on secular trends in childhood smoking rates and compared with smoking rates at fixed ages. They also described secular trends regarding the prevalence of smoking at fixed ages. The variations in smoking rate of young children and adolescents by follow-up groups have not been studied by follow-up groups at a national level. Objective: We looked at trends and generational impacts on smoking rate by using follow-up groups of male Japanese high school students to quantitatively assess differences in trends, based on multiple nationwide data from the Japanese Youth Tobacco and Drinking Surveys gathered every 4 years between 1996 and 2008. Methods: The surveys were nationwide, cross-sectional random sampling surveys given every 4 years from 1996 to 2008, using the single-stage cluster sampling methodology. The cluster unit of the sampling was school. The survey targeted junior and senior high school students from schools selected through Japan using the National School Directory. Students enrolled in the sampled schools were subjects of the study. Participants were 53,925 high school students from 7th grade to 11th grade in 1996, 2000, 2004 and 2008. We divided the three follow-up groups every 4 years
\end{abstract}

from 1996 to 2004 for male junior high school students in 7th grades, age 13 . The end periods were 4 years later when they had become 11th graders, age 17, from 2000 to 2008. Main outcome measures in this study were life time smoking, current smoking within 30 days and daily smoking at 7th or 11th grade and the trend of the smoking rates between 7th to 11th grades. Results: Life time smoking rate, current smoking rate and daily smoking rate in Japanese high school students decreased at 7 th grade from 1996 to 2004. They also decreased at 11th grade from 2000 to 2008. However, the slopes differed among their follow-up groups. The increments in their smoking rates from 7 th grade to 11th grade in male high school students were smaller in recent follow-up groups both in 2000 and in 2004 than in follow-up groups in 1996. Then, those increments in follow-up groups between in 2000 and in 2004 were similar in lifetime smoking rate and current smoking rate. Conclusions: We have shown that monitoring trends by follow-up group are important in studying smoking for public health. Values of smoking rates from a young age to adolescence by follow-up group should be examined. Values of smoking rate and regular changes in smoking rate are important because smoking rate changes dynamically during adolescence. Not only trends in smoking rates at fixed ages, but also generational impacts should be considered by using follow-up groups to 


\begin{abstract}
study smoking behaviors among students. We need to continue careful monitoring of follow-up group smoking prevalence. When long-term health promotions are planned or assessed, policy makers need to look at changes in followup groups.
\end{abstract}

\section{Keywords: Smoking Rates; Repeated \\ Cross-Sectional Study; Nationwide Survey; Japan}

\section{INTRODUCTION}

Smoking in childhood has become an important public health concern because early smoking is considered to result in smoking in later life and a higher prevalence of smoking-related disorders [1]. Thus, monitoring changes in smoking rate over time is helpful [1]. Several papers have reported on secular trends in childhood smoking rates, compared smoking rates at fixed ages, and described secular trends regarding the prevalence of smoking, as defined by smoking rate [2-5]. Most of these studies have shown increasing smoking rates and a prevalence of smoking in children.

Smoking rates of young children and adolescents have also been reported [6]. However, most of these data were based on cross-sectional studies. When estimating the rate increment for a follow-up group, the slope may be distorted by cohort effects [7-9]. The shapes of trends of young children and adolescents by studying follow-up groups have not been examined at a national level. The variations in smoking rate of young children and adolescents by follow-up groups have not been studied by follow-up groups at a national level, and no reported study has compared trends among multiple follow-up groups in a nation.

Frequent observations are needed to compare trends in smoking rates among multiple follow-up groups belonging to the same grade in different years. In this study, we looked at trends and generational impacts on smoking rate by using follow-up groups of male Japanese high school students to quantitatively assess differences in trends. We used nationwide data from the Japanese Youth Tobacco and Drinking Surveys, gathered every 4 years between 1996 and 2008.

\section{METHODS}

\subsection{Subjects and Procedure}

The surveys were nationwide, cross-sectional random sampling surveys given every 4 years from 1996 to 2008, using the single-stage cluster sampling methodology [10]. Previous studies detailing the Japanese Youth Tobacco and Drinking Surveys have been reported [2,11-13]. The cluster unit of the sampling was schools. The survey tar- geted junior and senior high school students from schools selected through Japan using the National School Directory. All students enrolled in the sampled schools were subjects of the study.

The number of schools sampled in the 1996 survey was 122 of 11,274 junior high schools (selection rate: $1.1 \%)$ and 109 of 5501 senior high schools (2.0\%). Respective values for the 2000, 2004 and 2008 surveys were 132 of 11,200 junior (1.2\%) and 102 of 5315 senior high schools (1.9\%) in the 2000 survey, 131 of 11,060 junior (1.2\%) and 109 of 5272 senior high schools $(1.9 \%)$ in the 2004 survey, and 130 of 10,955 junior (1.2\%) and 110 of 5115 senior high schools (2.0\%) in the 2008 survey.

We requested the cooperation of the principals of these schools and sent these individuals questionnaires for their respective school's student population. The teachers were asked to inform the students of the voluntary nature of their participation and to urge them to answer honestly. Anonymous questionnaires and envelopes were handed to the students for completion during school time. Upon completion, the questionnaires were sealed in the envelopes by the students themselves, collected by their teachers, and returned to our researchers unopened. This survey was reviewed and approved by the institutional review board of Nihon University (No. 19-5-0).

\subsection{Questionnaire}

The questionnaire focused on smoking experience, smoking frequency, and age. Experimenting smokers, current smokers, and daily smokers were defined as those who had tried smoking at least once, those who had smoked at least once during the previous 30 days, and those who had smoked every day during the previous 30 days, respectively.

\subsection{Responses}

For the 1996 survey, responses were obtained from 80 junior (response rate 65.5\%) and 73 senior high schools (67.0\%). In 2000, the respective values were 99 (75.0\%) and 77 schools $(75.5 \%)$, and in 2004, there were 92 (70.2\%) and 87 schools (79.8\%). In 2008, the respective values were 92 (70.8\%) and 73 schools (72.7\%).

We used data from the 1996-2004 surveys for male junior high school students in 7th grade, age 13 . We divided to the three follow-up groups every 4 years from 1996 to 2004. The end periods were 4 years later when they had become 11th graders, age 17, from 2000 to 2008. Table 1 shows a summary of follow-up groups. All group data includes all of the smoking rates from 7th grade to 11th grade. The total sample size of the 1996-2008 surveys was 53,925. We compared smoking rate increments from 7 th to 11th grade for 3 follow-up 
Table 1. Follow-up groups of male students in this survey, Japan, 1996-2008.

\begin{tabular}{ccccc}
\hline \multirow{2}{*}{$\begin{array}{c}\text { Follow-up } \\
\text { groups }\end{array}$} & \multicolumn{2}{c}{ Years of Measurement } & \multicolumn{2}{c}{ Sample size } \\
\cline { 2 - 5 } & $\begin{array}{c}\text { Year in } \\
\text { 7th grade }\end{array}$ & $\begin{array}{c}\text { Year in } \\
11^{\text {th }} \text { grade }\end{array}$ & $\begin{array}{c}\text { Number of } \\
7^{\text {th }} \text { grade }\end{array}$ & $\begin{array}{c}\text { Number of } \\
11^{\text {th }} \text { grade }\end{array}$ \\
\hline 1996 group & 1996 & 2000 & 7211 & 9662 \\
2000 group & 2000 & 2004 & 8248 & 12,241 \\
2004 group & 2004 & 2008 & 6917 & 9646 \\
\hline
\end{tabular}

groups as well as each smoking rate in both 7th grade and 11th grade for 3 follow-up groups.

\subsection{Statistical Analysis}

The percentages in the tables were calculated by a weighting method based on one-stage stratified cluster sampling10. We estimated the mean values of smoking rate by follow-up group. We calculated the change in smoking rate by subtracting the previous smoking rate from the current one, by follow-up group. Data were analyzed using the SPSS ver. 21.0 software (SPSS, Tokyo, Japan).

\section{RESULTS}

\subsection{Trends of Lifetime Smoking Rates}

Figure 1 shows the trends of the lifetime smoking rate for the three follow-up groups (1996, 2000 and 2004) of Japanese male students from 7 th grade to 11th grade. The lifetime smoking rates decreased at 7 th grade from 1996 to 2004 in males. They also decreased at 11th grade from 2000 to 2008. However, the increments in the lifetime smoking rate from 7th grade to 11th grade in high school students were smaller in recent follow-up groups both in 2000 and in 2004 than in follow-up groups in 1996. Then, those increments in follow-up groups between 2000 and 2004 were similar; around $+13 \%$ in males from 7 th grade to 11 th grade.

\subsection{Trends of Current Smoking Rates}

Figure 2 shows the trends for current smoking rate for male students from 7th grade to 11th grade for three follow-up groups $(1996,2000,2004)$. The current smoking rates decreased at 7th grade from 1996 to 2004 in males. They also decreased at 11th grade from 2000 to 2008. However, the current smoking rate increments from 7 th grade to 11th grade were smaller in recent follow-up groups, both in 2000 and in 2004, than in follow-up groups in 1996. Increments in follow-up groups between 2000 and 2004 were similar; $+6.6 \%$ $8.0 \%$ in males from 7 th grade to 11 th grade.

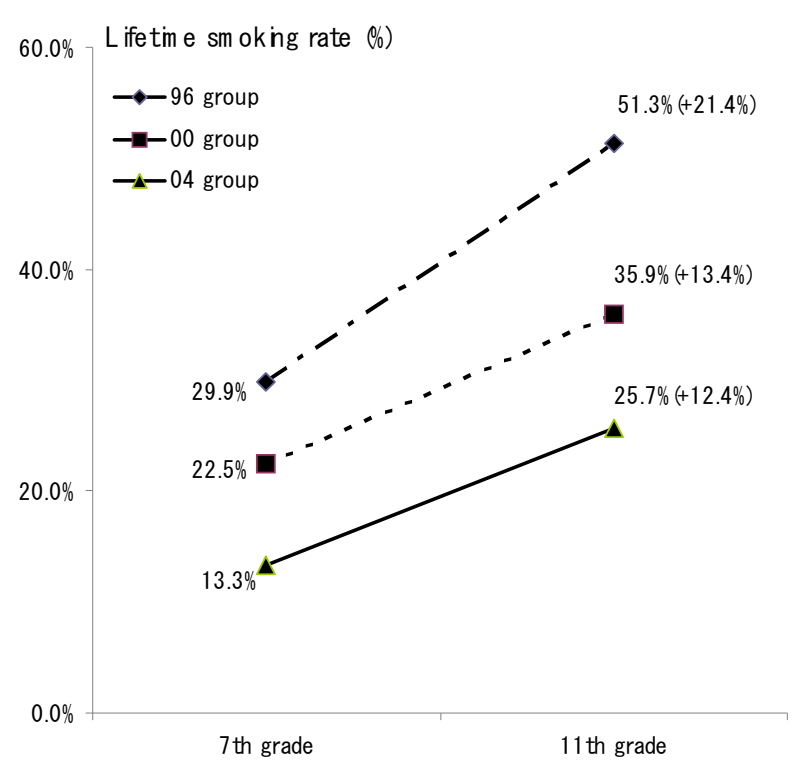

Figure 1. Lifetime smoking rate trends among male 7th - 11th graders by three follow-up groups (1996, 2000, 2004).

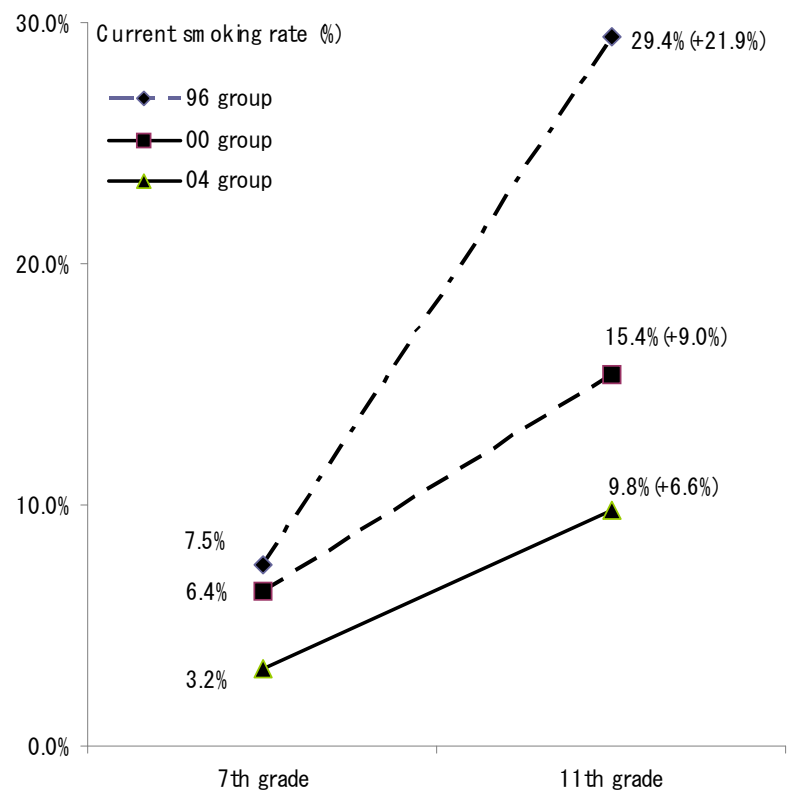

Figure 2. Current smoking rate trends among male 7th - 11th graders by three follow-up groups (1996, 2000, 2004).

\subsection{Trends of Daily Smoking Rates}

Figure 3 shows the trends for daily smoking rate for male students from 7th grade to 11th grade for three follow-up groups (1996, 2000, 2004). The daily smoking rates decreased at 7th grade from 1996 to 2004 both in males and females. They also decreased at 11th grade from 2000 to 2008 . However, the daily smoking rate increments from 7 th grade to 11th grade grew gradually smaller from the 1996 follow-up group to the 2004 follow-up group; $+17.5 \%$ in the 1996 group, $+7.6 \%$ in 


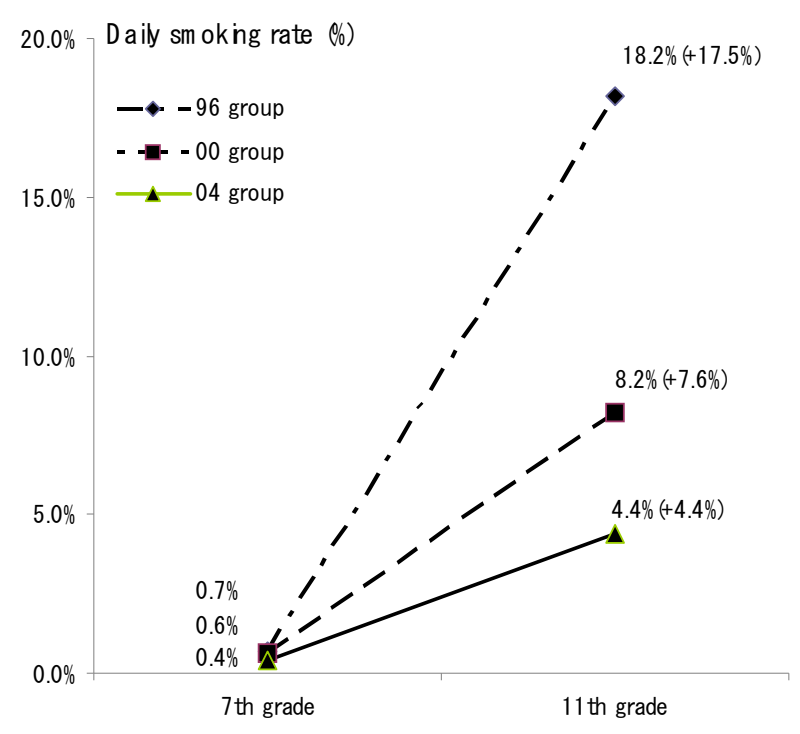

Figure 3. Daily smoking rate trends among male 7th - 11th graders by three follow-up groups (1996, 2000, 2004).

the 2000 group and $+4.0 \%$ in the 2004 group.

\section{DISCUSSIONS}

Smoking rates for more recent male students' followup groups from 7th grade to 11th grade in Japan were relatively lower than older follow-up groups in 1996. Recent smoking rate increments from 7th grade to 11th grade were stable in the 2000 and 2004 follow-up groups, though all smoking rates decreased in both 7th and 11th grade from 1996 to 2004. Recently, smoking in adolescence has become an important public health concern worldwide because early smoking is considered to result in nicotine dependence in later life, as well as a high prevalence of tobacco-related disorders [1]. To our knowledge, this is the first report to show the generational impact of smoking from 7th grade to 11th grade by follow-up groups. Our results show the importance of observing trends of smoking rates by using follow-up groups and monitoring a wide span of 4 years, not only at 7 th grade but also at 11 th grade.

\subsection{Decreasing Factors of Smoking in Minors}

Although our study was restricted to the period from 7th grade to 11th grade, the smoking rate of the followup groups at 11th grade increased in each survey. Smoking rate is generally considered to increase with age. In recent follow-up groups, there has been a trend towards a decreased prevalence of smoking among adolescents in Japan. There are several reasons to explain this result. First, human factors may influence who smokes. Parental smoking is one of the most important factors of adolescent smoking [14-16]. A decrease in the prevalence of smoking by adult men, including their fathers, probably contributed to the decrease among students. Peer smoking is also a well-known factor of adolescent smoking [17]. The decreased prevalence of smoking among students may also have contributed to a decrease in peer pressure to start smoking [18]. Second, some revised or established restrictions about adolescent smoking may relate to a decrease in smoking among students. A revision of the Act to Prohibit Minors from Smoking requires tobacco retailers to strictly enforce verification of customer age from official documentation. Based on the Health Promotion Law issued in 2002, there is a movement by local governments to encourage a smoke-free school site policy with the aim of preventing passive smoking in schools. Card-based proof-of-age systems in tobacco vending machines in Japan were introduced throughout Japan in March, 2008 [19]. However, a significant number of adolescent smokers still buy their cigarettes in stores, and most of the current smokers purchase their cigarettes using cigarette vending machines. Age verification cards fail to fully prevent minors from accessing tobacco products, especially among students who are daily smokers [19]. Previous studies have reported a total ban on smoking at school (the entire school site) being an effective measure in preventing adolescent smoking [20,21]. However, the inappropriate influence of teachers smoking outside the school buildings in full view of students may offset the effect of a school policy restricting smoking. Finally, cigarette prices in Japan were raised two times, in 1998 and 2003, each time by 20 yen (US\$0.22) per pack (20 cigarettes). The increased price of a pack of cigarettes may mean greater difficulty obtaining cigarettes for adolescents. However, each follow-up group in 1996 and 2000 was affected by the price rise, with different smoking rate results, so it is difficult to explain a decrease in prevalence being caused by higher prices. Confirmation of the persistence of this decrease in prevalence will require regular monitoring of adolescent smoking prevalence and related factors.

\subsection{Smoking Rates of Other Nations in Minors}

Considering the worldwide smoking epidemic rates in adolescents, prevention of smoking in the earlier stages of life is an important public health priority. In a number of western countries: USA [22], England [23], Australia [24], and Canada [25], a decreased prevalence of smoking was seen in high school students from 2000 to 2004. Japan tended to not have as many high school smokers as other developed countries in recent times. However, Italy, Russia [26], Hungary, and Latvia [27] did not have a decrease. There are global trends to ban smoking among 
adolescents based on the Framework Convention on Tobacco Control (FCTC) [28]. Some countries may have begun taking action quickly to ensure implementation of this convention. Our study focused on generational impacts on smoking by looking at follow-up groups. Few studies clarified these impacts in the world. In the future, the effects of generational impact need to be considered when monitoring follow-up groups for smoking prevalence.

\subsection{Repeated Cross-Sectional Study}

A specific feature of this study was the use of a nationwide, repeated, cross-sectional survey with random sampling to show the slope by follow-up group. In a cross-sectional study, each student at 7th grade is observed once, and in a longitudinal study each student is observed two times. In a repeated, cross-sectional survey, each student is observed once, but each follow-up group is studied two times. Thus, we can infer the slope of a follow-up group from a repeated, cross-sectional survey. A repeated, cross-sectional survey is usually reported as a cross-sectional curve by survey year [29], but such a cross-sectional slope is different from the slope of a follow-up group when a follow-up group effect occurs. In a cross-sectional slope, we see combined effects of follow-up group and year. When interpreting smoking rates twice, as we did here, the follow-up group effect should be considered. A repeated, regular survey is suited to monitoring trends by follow-up group because trends can be produced and checked for gradual changes by generation. The weakness of a repeated, cross-sectional survey, compared with a longitudinal study, is that all inferences are described in terms of population averages, and the variability of trends among individuals and the effects of covariates cannot be inferred. The slopes of the smoking rate obtained by following a single person longitudinally and that obtained by population average are well known to be different because the timing of smoking initiation varies greatly between individual people [30]. A repeated, cross-sectional survey and a longitudinal study should be considered as being complementary.

\subsection{Limitations}

One limitation of this study is the possibility of misclassification of smoking status among students. Although this study uses an anonymous questionnaire survey, the respondents may have been reluctant to report their actual smoking status due to more active antismoking policies in recent years. However, we considered the influence of misclassification of reported smoking status to not be large because the number of questionnaires with invalid or contradictory answers did not increase during this study period. Confirmation of the persistence of this decrease in prevalence will require periodic monitoring of adolescent smoking prevalence and related factors.

\subsection{Conclusion}

Smoking rates among Japanese male students decreased both at 7 th grade and at 11th grade. However, the smoking rate increments from 7 th grade to 11th grade were smaller in recent follow-up groups than in older follow-up groups, which means most Japanese high school students did not start smoking cigarettes in the early 2000s. We have shown that monitoring trends by follow-up group are important in studying smoking for public health. Values of smoking rates from a young age to adolescence by follow-up group should be examined. For this purpose, a repeated, cross-sectional survey is suitable. Values of smoking rate and regular changes in smoking rate are important because smoking rate changes dynamically during adolescence. Not only trends in smoking rates at fixed ages, but also generational impacts should be considered by using follow-up groups to study smoking behaviors among students. In the future, we need to continue careful monitoring of follow-up group smoking prevalence. When long-term health promotions are planned or assessed, policy makers need to look at changes in follow-up groups.

\section{ACKNOWLEDGEMENTS}

We are grateful to Mr. Michita Nagastuka, Ms. Sanae Numaguchi and Ms. Kyoko Kawamoto for the assembling of the data, and to Ms. Jenifer Shunk Monma for the English editing of the manuscript. This study was supported by a grant for a Special Research Project in 1996 and a Public Health Research Projects in 2000, 2004 and 2008 from the Ministry of Health and Welfare Health Science Research Fund in Japan. The sponsors of this study had no role in study design, data collection, data analysis, data interpretation and writing of the paper. Conflicts of interests: No declared.

\section{REFERENCES}

[1] Warren, C.W., Jones, N.R., M.P. Eriksen and Asma, S. (2006) Global Tobacco Surveillance System (GTSS) collaborative group: Patterns of global tobacco use in young people and implications for future chronic disease burden in adults. Lancet, 367, 749-753. doi:10.1016/S0140-6736(06)68192-0

[2] Osaki, Y., Minowa, M.. Suzuki, K. and Wada, K. (2003) Adolescent smoking behavior in Japan, 1996. Japanese Journal of Alcohol and Drug Dependence, 38, 483-491.

[3] Global Youth Tabacco Survey Collaborative Group (2002) Tobacco use among youth: A cross country comparison. Tobacco Control, 11, 252-270. doi:10.1136/tc.11.3.252

[4] Warren, C.W., Jones, N.R., Peruga, A., Chauvin, J., 
Baptiste, J.P., Costa de Silva, V., el Awa, F., Tsouros, A., Rahman, K., Fishburn, B., Bettcher, D.W., Asma, S. and Centers for Disease Control and Prevention (CDC) (2008) Global youth tobacco surveillance, 2000-2007. MMWR Publications, Surveillance Summary, 57, 1-28.

[5] Chen P.L., Huang, W., Chuang, Y.L., Warren, C.W., Jones, N.R. and Asma, S. (2008) Prevalence of tobacco use among junior high and senior high school students in Taiwan. Journal of School Health, 78, 649-654. doi:10.1111/j.1746-1561.2008.00361.x

[6] US Department of Health and Human Services (1994) Preventing tobacco use among young people: A report of the surgeon general. US Department of Health and Human Services, Public Health Service, Centers for Disease Control and Health Promotion, Office on Smoking and Health, Atlanta.

[7] Szklo, M. and Niet, F.J. (2000) Epidemiology: Beyond the basics. Aspen Publishers, Frederick.

[8] Twisk, J.W.R. (2003) Applied longitudinal data analysis for epidemiology: A practical guide. Cambridge University Press, Cambridge.

[9] Fitzmaurice, G.M., Laird, N.M. and Ware, J.H. (2004) Applied longitudinal analysis. John Wiley \& Sons, Hoboken.

[10] Cochran, W.G. (1977) Single-stage cluster sampling: Clusters of unequal sizes. In: Sampling Techniques, 3rd Edition, Wiley, New York, 249-273.

[11] Osaki, Y., Minowa, M., Suzuki, K. and Wada, K. (2004) Nationwide survey on adolescent smoking behavior in Japan, year 2000. Kosei no Shihyo, 51, 24-32.

[12] Osaki, Y., Tanihata, T., Ohida, T., Minowa, M., Wada, K., Suzuki, K., Kaetsu, A., Okamoto, M. and Kishimoto, T. (2006) Adolescent smoking behaviour and cigarette brand preference in Japan. Tobacco Control, 15, 172-180. doi:10.1136/tc.2005.013060

[13] Osaki, Y., Tanihata, T., Ohida, T., Kanda, H., Kaneita, Y., Minowa, M., Suzuki, K., Wada, K. and Hayashi, K. (2008) Decrease in the prevalence of smoking among Japanese adolescents and its possible causes: Periodic nationwide cross-sectional surveys. Environmental Health and Preventive Medicine, 13, 219-226. doi:10.1007/s12199-008-0033-1

[14] Bricker, J.B., Peterson Jr., A.V., Leroux, B.G., Andersen, M.R., Rajan, K.B. and Sarason, I.G. (2006) Prospective prediction of children's smoking transitions: Role of parents' and older siblings' smoking. Addiction, 101, 128-136. doi:10.1111/j.1360-0443.2005.01297.x

[15] Soteriades, E.S. and Di Franza, J.R. (2003) Parent's socioeconomic status, adolescents' disposable income, and adolescents' smoking status in Massachusetts. American Journal of Public Health, 93, 1155-1160. doi:10.2105/AJPH.93.7.1155

[16] Farkas, A.J., Gilpin, E.A., White, M.M. and Pierce, J.P. (2000) Association between household and workplace smoking restrictions and adolescent smoking. JAMA, 284, 717-722. doi:10.1001/jama.284.6.717

[17] Alexander, C., Piazza, M., Mekos, D. and Valente, T. (2001) Peers, schools, and adolescent cigarette smoking. Journal of Adolescent Health, 29, 22-30. doi:10.1016/S1054-139X(01)00210-5

[18] Powell, L.M., Tauras, J.A. and Ross, H. (2005) The importance of peer effects, cigarette prices and tobacco control policies for youth smoking behavior. Journal of Health Economics, 24, 950-968. doi:10.1016/j.jhealeco.2005.02.002

[19] Kanda, H., Osaki, Y., Ohida, T., Kaneita, Y. and Munezawa, T. (2011) Age verification cards fail to fully prevent minors from accessing tobacco products. Tobacco Control, 20, 163-165. doi:10.1136/tc.2010.036947

[20] Moore, L., Roberts, C. and Tudor-Smith, C. (2001) School smoking policies and smoking prevalence among adolescents: Multilevel analysis of cross-sectional data from Wales. Tobacco Control, 10, 117-123. doi:10.1136/tc.10.2.117

[21] Wold, B., Currie, C., Roberts, C. and Aaroe, L.E. (2004) National legislation on school smoking restrictions in eight European countries. Health Promotion International, 19, 482-488. doi:10.1093/heapro/dah410

[22] Office on Smoking, Health, and Division of Adolescent and School Health (2004) Cigarette use among high school students, United States, 1991-2003. MMWR, 53, 499-502.

[23] National Centre for Social Research (2006) Drug use, smoking and drinking among young people in England in 2005. NHS Health and Social Care Information Centre, Public Health Statistics, National Health Service, London.

[24] White, V. and Hayman, J. (2003) Smoking behaviours of Australian secondary students in 2002. National drug strategy monograph series No. 54. Department of Australian Government, Canberra.

[25] Health Canada (2005) The national strategy: Moving forward? The 2005 progress report on tobacco control. The obacco Control Liaison Committee, Ottawa.

[26] Hibell, B., Anderson, B., Bjarnason, T., et al. (2004) The ESPAD (European School Survey Project on Alcohol and Other Drugs) report. The Swedish Council for Information of Alcohol and Other Drugs, Stochholm.

[27] Hublet, A., De Bacquer, D., Valimaa, R., Godeau, E., Schmid, H., Rahav, G. and Maes, L. (2006) Smoking trends among adolescents from 1990 to 2002 in ten European countries and Canada. BMC Public Health, 6, 280. doi:10.1186/1471-2458-6-280

[28] Taylor, A.L. and Bettcher, D.W. (2000) WHO framework convention on tobacco control: A global "good" for public health. Bulletin of the World Health Organization, 78, 920-929.

[29] Kiriike, N., Nagata, T., Sirata, K. and Yamamoto, N. (1999) Are young women in Japan at high risk for eating disorders? Decreased BMI in young females from 1960 to 1995. Psychiatry and Clinical Neurosciences, 52, 279-281. doi:10.1046/j.1440-1819.1998.00387.x

[30] Tanner, J.M., Whitehouse, R.H. and Takaishi, M. (1966) Standards from birth to maturity for height, weight, height velocity, and weight velocity: British children, 1965 part I. Archives of Disease in Childhood, 41, 454-471. $\underline{\text { doi:10.1136/adc.41.219.454 }}$ 